\title{
El cardenal de San Jorge y los hombres de negocios genoveses en Cuenca durante el reinado de los Reyes Católicos
}

\author{
Máximo Diago Hernando*
}

\section{RESUMEN}

Tras el nombramiento del italiano Rafael Sansoni Riario como obispo de Cuenca en 1493 se instalaron en esta ciudad, $y$ en otras del obispado como la de Huete, varios hombres de negocios genoveses, que se encargaron de la recaudación de las rentas de este obispo absentista. $S u$

presencia en estas ciudades, en donde compitieron con los mercaderes locales en los negocios financieros $y$ mercantiles, dio lugar al planteamiento

de múltiples conflictos, en algunos casos muy violentos. En este artículo

se da cuenta de los factores que propiciaron el auge del sentimiento antigenovés en Cuenca durante el reinado de los Reyes Católicos, y de las actividades que desarrollaron en el ámbito conquense los hombres de negocios genoveses vinculados con

Rafael Sansoni Riario.

\section{SUMMARY}

After the Italian Cardinal Rafael Sansoni Riario was appointed bishop of Cuenca in 1493, several merchants from Genoa established themselves in the main towns of this Castilian diocese, in orden to collect the rents that belonged to this absentist bishop in the diocese. Their presence in these towns, where they competed with the local merchants in finance and trade, caused many conflicts, even violent ones. In this article the autor pays attention to the main factors that propitiated the emergence of an anti-Genoese feeling among the population in Cuenca at the end of the fifteenth century. And he gives account of the main activities in Cuenca of these Genoese merchants that were at the service of the Cardinal Rafael Sansoni Riario.

* Doctor en Historia por la Universidad Complutense. Investigador contratado del CSIC. Institución Milá y Fontanals. Barcelona. 
El seguimiento de las actividades como hombres de negocios de los genoveses en el reino de Castilla durante la Baja Edad Media y la temprana Edad Moderna constituye una apasionante tarea para el historiador, y se puede abordar desde muy diversas perspectivas. Hasta ahora las investigaciones dedicadas a esta cuestión han sido muy numerosas, aunque es cierto que se han volcado más sobre el ámbito andaluz ${ }^{1}$, y sobre los negocios de los genoveses en la Corte durante la época de los Austrias $^{2}$. En contrapartida otras facetas menos espectaculares de las actividades de los genoveses en Castilla han sido mucho menos atendidas, y por ello todavía queda abierto un amplio espacio para la investigación en torno a esta cuestión.

Entre estas facetas habría que mencionar por ejemplo la de administradores del cobro de rentas eclesiásticas, que abrió el camino a los negocios castellanos a determinadas familias genovesas, sobre todo cuando los beneficiarios de las referidas rentas fueron clérigos italianos, o más en concreto genoveses. $Y$ a este respecto no hay que olvidar que en la segunda mitad del siglo $\mathrm{XV}$ hubo varios papas genoveses que, practicando abiertamente la política del nepotismo, colmaron en ocasiones de beneficios eclesiásticos en Castilla a algunos de sus parientes.

Uno de estos papas de origen genovés fue el cardenal Franceso della Rovere, que tras su elección el 9 de agosto de 1471 adoptó el nombre de Sixto iV. Su familia tenía su origen en un humilde tejedor ligur, y él durante los años en que estuvo ocupando el solio pontificio trató por todos los medios a su alcance de asegurar la promoción de sus parientes más cer-

\footnotetext{
1 Una visión de conjunto sobre el papel de los genoveses en Castilla en los siglos XVI y XVII en E. OTTE, "ll Ruolo dei Genovesi nella Spagna del XV e XVI secolo», en La reppublica internazionale del denaro tra XV e XVII secolo, Bologna, 1986, págs. 17-56. De este mismo autor, "Kastilisch-genuesische Wirtschafts-und Finanzinteressen bei der Einführung der Negersklaverei in Amerika" Gesammelte Aufsätze zur Kulturgeschichte Spaniens, 22 (1965), págs. 283-320. También R. PIKE, Enterprise and Adventure. The Genoese and the Opening of the New World, Ithaca, 1966. Sobre los genoveses en Málaga Vid. J.E. LÓPEZ DE COCA, «LOS genoveses en Málaga durante el reinado de los Reyes Católicos» $A E M, 10$ (1980), págs. 619-50. Y «Mercaderes genoveses en Málaga (1487-1516). Los hermanos Centurión e Ytalián» HID, 7 (1980), págs. 93-126. Sobre los genoveses en Sevilla vid. M.A. LADERO QUESADA, "Los genoveses en Sevilla y su región (siglos XIII-XVI): elementos de permanencia y arraigo» en Los mudéjares de Casilila y otros estudios de historia medieval andaluza, Granada, 1989. y J.M. BELLO LEÓN, «Mercaderes extranjeros en Sevilla en tiempos de los Reyes Católicos" HID, 20 (1993), págs. 47-83. Fuera del ámbito andaluz han recibido también una cierta atención los genoveses presentes en la Murcia bajomedieval. Vid. A.L. MOLINA MOLINA, «Mercaderes genoveses en Murcia durante la época de los Reyes Católicos (1475-1516)" MMM (1976), pấgs. 277-312. Y J. TORRES FONTES, “Genoveses en Murcia (Siglo XV)» MMM, (1976), págs. 69-168.

Vid. F. RuIz MARTiN, «Los hombres de negocios genoveses de España durante el siglo XV|» en H. KelLenBenz (Ed.), Fremde Kaufleute auf der Iberischen Haldinsel, Colonia-Veiene, 1970, págs. 84-99. También D. OTTE, «ll ruolo..."
} 
canos tanto en el seno de la Iglesia como en la propia sociedad política italiana, buscando incluso una vinculación con la casa de Nápoles. Los dos miembros de su familia a los que más favoreció fueron el cardenal Pedro Riario, que no obstante murió ya el 5 de enero de 1474 a la edad de 28 años, víctima de los excesos de todo género cometidos en su corta vida, y el cardenal Julián della Rovere, quien le sobrevivió, y alcanzó una enorme ascendencia en la corte pontificia bajo el pontificado del también genovés Inocencio VIII, miembro de la familia Cibo. Este cardenal protagonizó entonces célebres episodios de enfrentamiento con los Borgia, y tras la muerte de Alejandro VI y el breve pontificado de transición de Pío III, consiguió acceder por fin al solio pontificio, adoptando el nombre de Julio II, con el que ha pasado a la historia ${ }^{3}$.

Menos célebre que la figura del cardenal Julián della Rovere resulta la de otro de los sobrinos del Papa Sixto IV, el cardenal de San Jorge, Rafael Sansoni Riario, puesto que su protagonismo en el escenario político italiano fue mucho menor. Para la historia de Castilla sin embargo este personaje resulta en cierta medida más familiar que su célebre pariente, a pesar de que no hay constancia de que en algún momento llegase a abandonar el territorio italiano para poner pies en suelo castellano, donde tantos beneficios eclesiásticos llegó a acumular. En efecto, tras la muerte de Pedro Riario, a quien Sixto IV había nombrado obispo de Sevilla ${ }^{4}$, este papa se volcó en conceder beneficios en Castilla a Rafael Sansoni Riario, quien como consecuencia se convirtió con seguridad en el italiano con intereses beneficiales más fuertes en Castilla durante el reinado de los Reyes Católicos, época en que, a pesar de la fuerte oposición demostrada por los monarcas, fueron ciertamente muy numerosos los italianos con beneficios eclesiásticos en Castilla ${ }^{5}$. Según los datos que proporciona Tarsicio de Azcona, y que como él mismo reconoce no son exhaustivos, este joven sobrino del Papa Sixto IV comenzaría a recibir beneficios eclesiásticos en

3 Vid. la reciente biografía de Julio II, que aporta bastantes datos sobre el proceso de ascenso de los della Rovere de Génova, de I. Cloulas, Jules II, Fayard, París, 1990.

4 El nombramiento tuvo lugar a la muerte del obispo Alfonso Fonseca, aunque al candidato papal se opusieron otros dos candidatos, uno propuesto por el cabildo, que fue el hermano del duque de Medinasidonia, y otro por el rey Enrique IV, que fue Pedro González de Mendoza. Pedro Riario murió sin haber llegado a tomar posesión del obispado, y tras su muerte siguió planteado el conflicto entre los otros dos candidatos, que finalmente se resolvió en favor de Mendoza. Vid. T. DE AzcoNA, La elección y reforma del episcopado español en tiempo de los Reyes Católicos, CSIC, Madrid, 1960, pág. 83.

5 Todavía durante el reinado de los Reyes Católicos muchos monasterios castellanos estuvieron en manos de abades comendatarios, en su mayoría de origen italiano y residentes en Roma, aunque estos monarcas trabajaron intensamente por acabar con esta práctica, apoyando decididamente la reforma observante. 
Castilla en enero de 1474, a raíz mismo de la muerte de Pedro Riario, al transferírsele los que éste había disfrutado, y en diversas ocasiones a lo largo de esta década fue acumulando muchos más, entre los que se podría destacar por ejemplo la abadía comendataria del monasterio de Parraces en Segovia ${ }^{6}$. Por otra parte en 1474 no sobrepasaba todavía la edad de 15 años, y cuando tan sólo contaba 20 su tío aprovechó la oportunidad ofrecida por la muerte del obispo de Cuenca, el cardenal Antonio Jacobo de Veneris, acaecida el 3 de agosto de 1479, para promoverle a la dignidad episcopal, nombrándole obispo de esta diócesis castellana ?.

Fue entonces cuando por primera vez el cardenal de San Jorge entró en contacto con la ciudad de Cuenca y su obispado, pero ante la decidida reacción de los Reyes Católicos para impedir que tomase posesión de la iglesia conquense, su nombramiento no resultó efectivo en aquella ocasión, prolongándose durante varios años el conflicto entre los monarcas castellanos y el Papa en torno a la provisión de este obispado.

A los efectos que aquí nos interesan importa ante todo recordar que en las negociaciones que entre 1479 y 1482 tuvieron lugar sobre este asunto entre Sixto IV y su sobrino el cardenal Rafael Sansoni Riario de un lado, y los Reyes Católicos de otro, actuó como intermediario entre ambas partes, en calidad de legado pontificio, el mercader genovés Domingo Centurión, quien había tenido anteriormente el cargo junto con otros mercaderes genoveses de depositario de la Cámara Apostólica ${ }^{8}$. Se trata del primer contacto del que hemos tenido noticia entre el cardenal de San Jorge y los hombres de negocios genoveses instalados en Castilla, y, aunque después de esta coyuntura no hemos vuelto a encontrar referencias sobre actuaciones en territorio castellano de Domingo Centurión o de otros miembros de su familia en representación de los intereses del cardenal, sí hemos podido constatar que éste recurrió repetidamente a hombres de negocios de Génova pará que se hiciesen cargo de la recaudación de sus rentas en Castilla, sobre todo después de su nombramiento como obispo de Cuenca por segunda vez. Antes de entrar en el análisis en profundidad de esta cuestión conviene sin embargo que demos cuenta de las circunstancias en que tuvo lugar la provisión definitiva de la sede de Cuenca en

Vid. T. de AzCONA, op. cit., págs. 109-110.

Sobre este nombramiento y sus consecuencias vid. T. DE AZCONA, op. cit., págs. 109 y ss.

8 Vid. T. DE AZCONA, op. cit, pág. 125. No hemos podido determinar la vinculación existente entre este Domingo Centurión y otros célebres genoveses de apellido Centurión residentes en Málaga, Sevilla y otras ciudades de la Península durante el reinado de los Reyes Católicos. Sobre éstos vid. en particular J.E. LóPEZ DE COCA, «Mercaderes genoveses... y y J.M. BELLO LEÓN, op. cit., págs. 53 y ss. 
Rafael Sansoni Riario, que se produjo bastantes años después de que hubiese sido designado para ocupar esta sede por su tío Sixto IV.

En efecto, la resistencia que en 1479 opusieron los Reyes Católicos a admitir al sobrino del Papa en la sede de Cuenca fue tan fuerte que finalmente, aunque sólo después de tres años de difícil negociación, gracias al acuerdo al que llegaron con Domingo Centurión en junio de 1482, consiguieron imponer a su candidato Alfonso de Burgos, admitiendo en contrapartida la ejecución de un plan de ajuste beneficial, por virtud del cual el cardenal de San Jorge obtuvo la iglesia de Salamanca, el cardenal de España, Don Pedro González de Mendoza, la de Osma, y el hasta entonces obispo de Osma, Francisco de Santillán, la de Córdoba ${ }^{9}$. El cardenal de San Jorge no quedó sin embargo plenamente satisfecho con el resultado obtenido, considerando que la diócesis de Salamanca no era de suficiente categoría para él, y por esto su tío Sixto IV aprovechó la primera oportunidad que se presentó, a la muerte del obispo de Toledo, Alonso Carrillo, ocurrida el 1 de julio de 1482, para mejorar su posición en la Iglesia de Castilla. Y lo consiguió, en pleno acuerdo con los Reyes Católicos, concediendo a éstos el nombramiento del hasta entonces obispo de Osma, el cardenal Mendoza, para la sede de Toledo, a cambio de que su sobrino, el cardenal de San Jorge, le sustituyese en la diócesis de Osma, que se consideraba de mayor prestigio que la de Salamanca ${ }^{10}$.

Rafael Sansoni Riario no llegó nunca a poner pies en territorio oxomense, puesto que en todo momento gobernó a través de un provisor, pero en los pocos años que duró su pontificado en esta diócesis se llegaron a plantear graves conflictos, que no hemos podido determinar si estuvieron en cierta medida motivados por su condición de extranjero, además de absentista, o constituyeron una última manifestación de las consecuencias de la división del obispado en dos bandos que se había producido años antes, cuando Luis Hurtado de Mendoza, hermano del conde de Castro, y candidato del cabildo catedralicio del Burgo de Osma, y Francisco de Santillán, el candidato papal, se habían enfrentado por aspirar ambos a la silla episcopal de Osma ${ }^{11}$.

9 Vid. T. DE AZCONA, op. cit., pág. 129.

10 T. DE AZCONA, op. cit., págs. 132-4.

11 Analizamos brevemente el episodio en Estructuras de poder en Soria a fines de la Edad Media, Valladolid, 1992, págs. 295 y ss. Una noticia que sugiere que los acontecimientos de 1492 pudieron guardar cierta relación con los de la división del obispado a fines de la década de 1470 , es la que refiere que los miembros del cabildo que se habían rebelado contra el obispo y su provisor habían llamado en su ayuda al alcaide de Gormaz, villa del señorío del conde de Castro, hermano de Luis Hurtado de Mendoza. 
Los episodios más graves tuvieron lugar ya hacia el final de su pontificado, en el año 1492, cuando varios canónigos de la catedral del Burgo de Osma, junto con otros laicos de la propia villa y de otras del entorno, se rebelaron abiertamente contra el cardenal de San Jorge y su provisor, el doctor Alonso García de Villalpando. Por una curiosa coincidencia estos episodios tuvieron lugar casi al mismo tiempo que se producía en Roma la muerte del Papa genovés Inocencio VIII, quien además de dejar hacer y deshacer en Roma al cardenal Julián della Rovere, también había favorecido con mercedes de beneficios en Castilla al pariente de éste, el cardenal de San Jorge ${ }^{12}$, y su sustitución en el solio pontificio por el que había sido principal enemigo del cardenal Della Rovere, el cardenal de origen valenciano Rodrigo de Borja, que adoptó el nombre de Alejandro VI. Entonces la facción "genovesa" constituida por los sobrinos de Sixto IV, con el cardenal Della Rovere a la cabeza, perdió su posición privilegiada en la corte pontificia, hecho que tuvo su plasmación más evidente en el abandono de su apartamento en el Vaticano por este último, y la instalación en su lugar de Ascanio Sforza. Dado que no tenemos pruebas documentales seguras, no nos atrevemos a afirmar que la rebelión de los canónigos burgenses contra su obispo el cardenal Rafael Sansoni Riario guardó relación directa con la pérdida de influencia en Roma de éste, y sobre todo de su pariente el cardenal Julián della Rovere, a raíz de la muerte de Inocencio VIII, pero la coincidencia cronológica de ambos procesos nos ha parecido significativa, y por ello hemos considerado conveniente llamar la atención sobre la misma.

Por tratarse de una cuestión que no afecta a los problemas centrales que nos ocupan en el presente artículo, no vamos a profundizar en el análisis de los acontecimientos ocurridos en Burgo de Osma en 1492, aunque para hacernos una idea de la gravedad de los mismos indicaremos que el provisor del cardenal, el doctor Alonso García de Villalpando, denunció ante el Consejo Real a Fernán Vázquez de Arce, administrador del priorazgo de la iglesia de Osma, Rodrigo de Tablares, capiscol, Pedro García de Camargo, adad de San Bartolomé de Ucero, y Pedro de Camargo y Juan de Vascuñana, canónigos de la catedral del Burgo, por haberse confederado y conspirado contra el cardenal y contra su señorío y jurisdic-

12 A la muerte de Juan de Villafañe, Inocencio VIII había transferido al cardenal de San Jorge, obispo de Osma, varios de los principales beneficios que éste tenía asignados en Castilla, y en concreto la abadía de San Guillermo, una canonjía en la catedral de León y una encomienda de la Orden Militar de Santiago, sita en los arrabales de León. Consta por una iniciativa al corregidor de León para que no se pongan impedimentos al cardenal en la toma de posesión de estos beneficios. AGS, RGS, XII-1491, fol. 68. 
ción sobre la iglesia y villa del Burgo, haciendo venir a esta villa muchos hombres de armas, que llegaron a acuchillar a algunos criados y familiares del cardenal, y a tratar incluso de tomar al asalto el palacio episcopal, donde estaban refugiados el provisor y muchos de sus hombres ${ }^{13}$.

Esta conjura del año 1492, que desconocemos con exactitud qué objetivo perseguía, debió dejar en cualquier caso mal sabor de boca al cardenal de San Jorge puesto que al año siguiente, sin que hayamos podido de momento precisar en qué circunstancias, procedió a permutar la diócesis de Osma con el obispo de Cuenca, Alfonso de Fonseca, y fue por esta vía como por fin consiguió ocupar la silla episcopal conquense, a la que años antes había tenido que renunciar por imposición de los Reyes Católicos ${ }^{14}$.

\section{EL PONTIFICADO DEL CARDENAL RIARIO EN CUENCA Y LOS CONFLICTOS ANTIGENOVESES}

Durante la etapa en que el cardenal de San Jorge fue obispo de Cuenca, tras la operación de permuta del año 1493, las reacciones de animadversión contra los genoveses se sucedieron en esta ciudad y en otras del obispado, como por ejemplo Huete, de forma continuada, poniendo de manifiesto que existía planteado un grave conflicto entre los hombres de negocios locales y estos otros hombres de negocios de origen italiano, que a juicio de los primeros se habian alzado a una posición privilegiada gracias al favor que les dispensaba el obispo.

En contrapartida llama la atención, sin embargo, que durante los años en que Rafael Sansoni Riario fue obispo de Osma, si bien es cierto que se vivieron días de grave conflicto en la capital del obispado con motivo de la conjura de algunos canónigos contra él y su provisor en el año 1492, por el contrario no hay constancia de que los vecinos del Burgo de Osma o de Soria o de otras ciudades del obispado denunciaran en alguna ocasión a genoveses que les estuvieran haciendo una competencia desleal en negocios de arrendamiento de beneficios eclesiásticos u otros. Quizás los hombres de negocios genoveses no estuvieron muy interesados en instalarse en el obispado de Osma, por no resultarles éste particularmente atra-

\footnotetext{
13 AGS, RGS, VII-1492, fol. 179. Comisión a Alonso Luzón, vecino de Soria, para que haga averiguaciones sobre los sucesos ocurridos en El Burgo de Osma, denunciados por el provisor Alonso García de Villalpando. Otras referencias en VI-1492, fol. 185; y II-1493, fol. 211. También analizamos brevemente estos episodios en Estructuras de poder en Soria... págs. 297 y ss.

14 Vid. T. Portillo Capilla, Instituciones del obispado de Osma, Soria, 1985, pág. 59.
} 
yente para llevar adelante las empresas mercantiles y financieras por ellos preferidas. $Y$, aunque ciertamente no disponemos de muchas pruebas documentales que confirmen esta hipótesis, sí que tenemos constancia al menos de que uno de los arrendadores que tomó a su cargo el cobro de las rentas del obispado de Osma siendo obispo el cardenal de San Jorge fue un judeoconverso castellano, avecindado en la villa de Aranda de Duero, Pedro de Santa Cruz, bien conocido por sus actividades como arrendador de impuestos durante el reinado de los Reyes Católicos ${ }^{15}$. Pero por otro lado también nos consta que en 1488 fue mayordomo y receptor de las rentas del cardenal en este obispado el genovés Bonacorso Bonacote.

El obispado de Cuenca, en cualquier caso, ofrecía más alicientes a los hombres de negocios genoveses para desplegar allí sus actividades por múltiples razones, y entre ellas quizás no era una de las menos importantes su propia situación estratégica, sumamente favorable para una actividad muy lucrativa, aunque también ilegal, en la que con frecuencia se vieron involucrados comerciantes y banqueros procedentes de Génova e instalados en Valencia: la saca de moneda hacia el reino valenciano ${ }^{16}$. De hecho, sin llegar a denunciar abiertamente operaciones ilegales de saca de moneda, los regidores de Cuenca en una acusación presentada ante el Consejo Real de 1513 contra los genoveses que tenían arrendado el obispado de Cuenca del cardenal de San Jorge, afirmaron sin rodeos que el principal perjuicio que se seguía de estos arrendamientos era que se sacaba todo el dinero que rentaban los beneficios eclesiásticos fuera del reino. Y a raíz de esta denuncia los reyes ordenaron al corregidor de Cuenca que averigüase quiénes habían sacado moneda fuera del reino en los últimos tres años, enviando a continuación la información obtenida al Consejo Real ${ }^{17}$.

Para evitar precisamente estos problemas de saca de moneda los monarcas en varias ocasiones prohibieron a los genoveses arrendar rentas eclesiásticas en Castilla, y más en particular en los obispados de Cuenca, Sigüenza y Osma, pero repetidamente estas prohibiciones dejaron de ob-

15 AGS, RGS, XI-1493, fol. 111. Se inserta una cédula en que se ordenaba a Pedro de Santa Cruz, arrendador del obispado de Osma por el cardenal de San Jorge, que pagase a los alcaides de las fortalezas de Osma, Ucero y Cabrejas, todas ellas pertenecientes al señorío episcopal. Sobre este individuo tratamos en nuestro artículo "Arrendadores arandinos al servicio de los Reyes Católicos" HID, 18 (1991), págs. 71-95.

16 Vid. M.A. LADERO QUESADA, "El banco de Valencia, los genoveses y la saca de moneda de oro castellana, 1500-1503» AEM, 17 (1987), págs. 571-594.

17 AGS, RGS, XI-1513. Comisión al corregidor de Cuenca. 
servarse, y así fue denunciado una y otra vez por los vecinos de Cuenca, aunque se advierte que estas denuncias proliferaron sobre todo en las dos primeras décadas del $x V{ }^{18}$, mientras que en la última del $\mathrm{XV}$, cuando ya era obispo de Cuenca el cardenal de San Jorge, apenas las hemos encontrado en la serie documental consultada, constituida esencialmente por el Registro General del Sello.

Los documentos consultados evidencian la existencia de una profunda hostilidad hacia los genoveses venidos al servicio del cardenal de San Jorge, sobre todo en las ciudades de Cuenca y Huete, hostilidad que bien pudo haber estallado, tras haberse venido gestando durante varios años, a raíz de la crisis de abastecimiento cerealero que se desencadenó en Castilla en los primeros años del siglo XVI, sobre todo después de la publicación en 1502 de la célebre pragmática que fijó unos precios de tasa para el cereal ${ }^{19}$.

Su condición de acaparadores de grandes cantidades de cereal, en circunstancias en que existían dificultades de aprovisionamiento de este valioso producto alimenticio, les debió convertir en blanco de las iras de muchos, pero sobre todo sus principales enemigos se encontraban entre los mercaderes y hombres de negocios locales, que se consideraban injustamente desplazados del negocio del comercio cerealero por extranjeros, a los que acusaban además de eximirse de cumplir con las obligaciones fiscales que pesaban sobre los naturales del reino de Castilla, al tiempo que extraían la riqueza fuera del mismo. Y de ahí que con frecuencia los motivos de denuncia contra los genoveses aludan también al disfrute por su parte de presuntos privilegios fiscales.

En concreto en varias ocasiones se presentaron denuncias contra determinados genoveses, siempre vinculados al cardenal de San Jorge, por

18 Entre otras denuncias de incumplimiento de la prohibición para genoveses del arrendamiento de beneficios, carnicerías, pescaderías y panaderías se pueden destacar: XII-1507 (es sobrecarta de una carta de IX-1507. No se denuncia a ningún genovés en particular). III-1509 (Se denuncia por incumplimiento a Vicencio Ferrer, Polo Gentil, Don Agustín de Espíndola y Lorenzo Gavoto). XI-1516 (Se denuncia por incumplimiento a Lorenzo Gavoto, Lorenzo Bosco y Peligro Gentil). XII-15 17 (Se denuncia por incumplimiento a Lorenzo Gavoto y Juan Embrón).

19 Sobre esta crisis de abastecimiento cerealero vid. entre otras obras E. IBARRA, El problema cerealista en España durante el reinado de los Reyes Católicos (1475-1516), Madrid, 1944. M.A. LADERO Quesada y M. GONZÁLEZ JiMÉnEZ, Diezmo eclesiástico y producción de cereales en el reino de Sevilla (1408-1503), Sevilla, 1979. Dos interesantes análisis monográficos en M. GonZÁLEZ JIMÉNEZ, "Las crisis cerealistas en Carmona» HID, 3 (1973), págs. 298-301. Y M. ASENJO GonzÁlez, Segovia. La ciudad y su tierra a fines del Medievo, Segovia, 1988, págs. 235-239. El caso de Cuenca por su parte es analizado con gran detenimiento por J.M. SÁNCHEZ BENITO, "Crisis de abastecimientos y administración concejil. Cuenca, 1499-1509" En la España Medieval, 14 (1991), págs. 275-306. 
no pagar el alcabala, amparándose en la posición privilegiada que les aseguraba su vinculación con el obispo. Así en 1503 Cristóbal de Peralta, en nombre de la ciudad de Huete, denunció que en los últimos tres años Nicoloso Adorno, mayordomo del obispo de Cuenca, no había sido incluido en los repartimientos de alcabalas, a pesar de que cada año había tratado en cuantía de más de dos millones de mrs., debido a que los repartidores, al tener contraídas con él deudas, probablemente por haberles vendido «al fiado» cereal en momentos de escasez, no le repartían alcabala a cambio de que les concediese plazo de espera en la devolución de las cantidades prestadas ${ }^{20}$. Y por su parte en 1511 Rodrigo del Castillo, vecino de Huete y arrendador de la renta del alcabala del pan en grano, denunció a varios genoveses estantes en Cuenca y en Huete que vendían en esta última ciudad grandes cantidades de pan en grano, y sin embargo se eximían de pagar alcabala porque, teniendo arrendados los frutos del obispado, alegaban que todo lo que vendían era del cardenal de San Jorge ${ }^{21}$.

Los sectores sociales con los que entraron en conflicto los genoveses en las ciudades de Cuenca y Huete, por razón de su actividad como arrendadores de rentas eclesiásticas y mercaderes de cereal, fueron varios, pero ante todo llama la atención que los enfrentamientos más graves los tuvieron con los propios miembros de la oligarquía conquense, porque en esta ciudad la dedicación de algunas familias de regidores al comercio y a los negocios especulativos, como era por ejemplo el arrendamiento de rentas, no tuvo un carácter en absoluto excepcional. En concreto tenemos noticias de que el regidor Fernán Gómez de Écija ordenó en 1508 a algunos de sus hombres que acuchillasen al contador del cardenal de San Jorge, Vicencio Ferrer, quien a raíz del intento frustrado de acuchillamiento protagonizado por éstos solicitó al rey licencia para llevar armas, y así defenderse de nuevos ataques ${ }^{22}$. Los motivos de la enemistad de este regidor hacia el genovés están por otra parte muy claros, ya que varios documentos nos informan que en 1508 Fernán Gómez de Écija había tomado a renta los frutos del arcedianazgo de Moya de Alonso Carrillo, arcediano de Moya, mientras que los genoveses Vicencio Ferrer y Polo y Andrea Gentil, alegaron que los referidos frutos les pertenecían a ellos, y para defensa de su causa consiguieron una citación penal contra el regidor conquense para que compareciese ante la Corte Romana, aduciendo que

20 AGS, RGS, $X-1503$, comisión al corregidor de Huete.

21 AGS, RGS, $X-1511$, comisión al corregidor de Cuenca y Huete.

22 AGS, RGS, II-1508. 
era persona poderosa y que por ello no podrían alcanzar de él justicia en Cuenca. En esta ocasión el rey, sin embargo, salió en defensa de la causa del regidor, por entender que la forma de proceder de los genoveses perjudicaba a la «real preeminencia», al haber buscado la intervención de un tribunal romano en un asunto interno de Castilla, y por ello llegó a ordenar que Vicencio Ferrer y Polo y Andrea Gentil fuesen apresados hasta que se consiguiese una revocación y anulación de la citación contra Fernán Gómez de Écija ${ }^{23}$.

A pesar, no obstante, de toda esta animosidad demostrada hacia los genoveses en Cuenca y Huete en los primeros años del XVI, las instituciones de gobierno local se vieron, sin embargo, en más de una ocasión forzadas a tener que recurrir a ellos para que se hiciesen cargo del aprovisionamiento de pan, incluso en aquellos momentos en que reales provisiones prohibían a los que no eran naturales del reino de Castilla tomar arrendamientos de panaderías en este obispado. Así por ejemplo consta que en agosto de 1502 el concejo de Cuenca, ante las dificultades con que se tropezaba en el abastecimiento de cereal, hizo gestiones para conseguir 5.000 fanegas del contador del cardenal ${ }^{24}$. Y el concejo de Huete por su parte consta que al menos en los años 1505 y 1506 se concertó con el contador del cardenal de San Jorge y otros genoveses para que éstos tomasen a su cargo el aprovisionamiento de cereal para el consumo de pan de la población de esta ciudad. En concreto tenemos constancia de que el 3 de julio de 1506 las autoridades de este concejo firmaron un acuerdo con Vicencio Ferrer, contador del obispo de Cuenca, y Lorenzo Gavoto, su mayordomo, en virtud del cual estos últimos se comprometieron a proporcionar para el consumo de la población de Huete en el período entre el 1 de septiembre de 1506 y 31 de julio de 1507 la cantidad de 7.500 fanegas de cereal. Dado, no obstante, que ellos eran extranjeros, y los reyes habían otorgado una provisión prohibiéndoles a los que no fuesen naturales de sus reinos el arrendamiento de panaderías, entre las cláusulas del contrato se incluyó una que obligaba al concejo de Huete a solicitar al Consejo Real una licencia especial autorizando a dichos genoveses a tomar a su cargo la panadería, se-

23 Tomamos las noticias de tres provisiones de AGS, RGS, III-1509. Aunque no hemos podido reconstruir en detalle la biogratía del regidor Fernán Gómez de Écija presumimos que tuvo una intensa dedicación al comercio especulativo del cereal porque fue él quien se opuso en 1500 a una ordenanza aprobada por el concejo conquense que fijaba un tope máximo de tres fanegas de trigo como cantidad que ningún vecino podía sobrepasar en sus compras cada semana. Vid. J.M. SÁNCHEZ BENITO, op. cit., pág. 278.

24 Vid. J.M. SÁnchez Benito, op. cit., pág. 285. 
mejante a la que se había obtenido el año anterior para Lorenzo Gavoto, de manera que si tal licencia no se conseguía el contrato quedaría inmediatamente anulado. Nos consta, no obstante, que la licencia se consiguió también en 1506, por lo que es seguro que al menos en dos ejercicios las panaderías de Huete estuvieron en manos de los genoveses que estaban en el obispado de Cuenca al servicio del cardenal de San Jorge ${ }^{25}$.

Estos ejemplos demuestran por tanto que toda la legislación antigenovesa arrancada de los monarcas por determinados sectores de la población conquense resultaba letra vacía ante la fuerza de los hechos, dado que los genoveses por tener la confianza del cardenal de San Jorge controlaban cada año una gran cantidad de cereal en el obispado, que representaba una reserva para el consumo local en época de dificultades de aprovisionamiento de la que no se podía prescindir. Y así lo demuestra por ejemplo el que del total de 7.500 fanegas de cereal que Vicencio Ferrer y Lorencio Gavoto se comprometieron a suministrar a la ciudad de Huete en el ejercicio 1506-1507 nada menos que 5.500 fuesen de las rentas del obispo, que ellos tenían el cargo de recaudar. No obstante las otras 2.000 fanegas tenían otra procedencia, quizás de los diezmos y otras rentas pertenecientes a otros beneficiados del obispado de Cuenca que ellos mismos habrían arrendado.

Ciertamente esta práctica les estaba prohibida, del mismo modo que el arrendamiento de panaderías, pero de nuevo en este caso consta que los propios clérigos beneficiados solicitaron licencias a la monarquía para poder arrendar sus beneficios a genoveses y otros extranjeros ${ }^{26}$. $Y$ este hecho confirma que, por muy odiados que fuesen los genoveses en la Cuenca del momento, se recurría con frecuencia voluntariamente a ellos para asuntos de negocios, seguramente porque su mayor capacidad financiera les permitía ofrecer mejores precios y mejores condiciones de pago a los usufructuarios de rentas en cereal que preferían cobrar éstas en dinero, entre los cuales el principal era por supuesto el propio obispo.

Algunas cláusulas del contrato de obligación de abastecimiento de la panadería de Huete del año 1506 dejan entrever, no obstante, que la posición de estos genoveses no era de absoluta prepotencia, sino que dependía en gran medida de la colaboración de las autoridades locales para

25 Vid. apéndice documental.

26. Así se hace constar expresamente en una provisión en AGS, RGS, XII-1507. 
conseguir recaudar las rentas y así poder disponer efectivamente de grandes cantidades de cereal. En concreto a este respecto son muy significativas las cláusulas que preveen la posibilidad de que hubiese dificultad en cobrar parte del cereal correspondiente al cardenal, bien porque éste estuviese en manos de arrendadores de la ciudad de Huete y su Tierra o bien porque algunos concejos de la Tierra se opusiesen a que saliese de sus términos para que su población no quedase desabastecida. En el primer caso, es decir, si los arrendadores se oponían a entregar las cantidades de cereal que se habían concertado en los arrendamientos, Vicencio Ferrer y Lorenzo Gavoto se comprometían a hacer todas las diligencias judiciales necesarias, hasta solicitar el auxilio del brazo seglar, para conseguir cobrar las rentas, pero en el caso de que todo el procedimiento resultase infructuoso, el propio concejo de Huete les libraba de la obligación de tener que responder por las cantidades no cobradas de las 5.500 fanegas que correspondían a las rentas del cardenal, que dejarían de entrar a las panaderías de Huete sin que por ello se pudiese penalizar a los abastecedores. Y para el caso de que fuesen los concejos de la Tierra los que se resistiesen a dejar salir el cereal del cardenal de sus términos, el concejo de Huete se obligaba a proporcionar favor, ayuda y gente a los genoveses para hacer frente a esta oposición, aunque de nuevo se preveía la posibilidad de que todos los esfuerzos fuesen vanos y no se consiguiese traer el cereal a la ciudad, en cuyo caso también se exoneraba a los genoveses de la obligación de tener que entregar para el consumo de la panadería las cantidades de cereal dejadas de percibir por esta razón.

En suma, pues, la actividad de los genoveses en el obispado de Cuenca en estos primeros años del siglo XVI, marcados por la crisis de abastecimiento cerealero en el reino de Castilla, estuvo determinada por factores muy diversos que tenían efectos contradictorios entre sí, por lo que su posición fue en todo momento inestable, aunque en contrapartida consiguieron mantenerla con más o menos dificultades durante mucho más tiempo del que hubiese resultado posible si se hubiesen aplicado con rigor las disposiciones antigenovesas arrancadas a la monarquía por determinados sectores de la sociedad conquense.

Por otra parte el sentimiento de animadversión hacia los italianos en general que se desarrolló en Cuenca durante el reinado de los Reyes Católicos, se tradujo también en el surgimiento de una fuerte oposición a la presencia en el obispado de beneficiados de esa procedencia. Así por ejemplo en 1513 se denunció a Agustín de Espíndola, obispo de Perusa, Pedro de Acosta, Miçer Jacobo y Miçer Carlos, todos ellos clérigos del círculo del cardenal de San Jorge en Cuenca, por haber acumulado más 
beneficios de los que les autorizaban las cartas de naturaleza ${ }^{27} . Y$ en 1516, a petición del deán y cabildo de la catedral de Cuenca, el Consejo Real otorgó una provisión confirmatoria de una pragmática que prohibía a los extranjeros tener beneficios en Castilla ${ }^{28}$.

La aparición de estos sentimientos anti-italianos en el seno de la sociedad conquense de la época resulta sin embargo perfectamente comprensible, si tenemos en cuenta las características que tuvo el pontificado del cardenal de San Jorge, para quien la dignidad episcopal de Cuenca no representaba más que una simple fuente de beneficios económicos, una prebenda de la que él podía disponer como si de un bien patrimonial se tratase. Y así lo demuestra el hecho de que en 1517 tratase de renunciar el obispado en su sobrino el arzobispo de Pisa, según se denunció en una provisión real dirigida a los concejos y justicias del obispado de Cuenca, conminándoles a que no obedeciesen las bulas apostólicas que pudiesen venir confirmando dicha renuncia ${ }^{29}$.

\section{RELACIÓN DE GENOVESES ARRENDADORES DE RENTAS ECLESIÁSTICAS EN EL OBISPADO DE CUENCA A PRINCIPIOS DEL SIGLO XVI}

- Adorno, Nicoloso. Mayordomo de rentas del obispo en 1503. Negocia en Huete.

- Bosco, Lorenzo. Arrendador del beneficio de Villanueva de la Jara y otros del obispado de Cuenca. 1516.

- Embrón, Juan. Arrendador en los años 1513-1517.

- Escaja, Bautista. Contador del obispo. $1502^{30}$.

- Espindola, Don Agustín de. Arrendador de rentas eclesiásticas. 1509. Protonotario apostólico. Fiador de Vicencio Ferrer en el contrato de aprovisionamiento de pan al concejo de Huete en 1506. En 1513 se le identifica como obispo de Perusa.

27 Vid. provisión dirigida a estos cuatro individuos en AGS, RGS, XII-1513. Cabe recordar que Agustín de Espíndola, siendo todavía simple protonotario apostólico, y Pedro de Acosta actuaron como fiadores de Vicencio Ferrer y Lorenzo Gavoto, cuando éstos tomaron a su cargo el abastecimiento de la panadería de Huete en 1506.

28 AGS, RGS, V-1516.

29 AGS, RGS, V-1517.

30 Vid. J.M. Bello León, op. cit., págs. 63-4. 
- Ferrer, Vicencio. Contador del cardenal de San Jorge. 1506-1508. Arrendador en el período 1504-9. Arrendador en 1513-1517 junto con Juan Embrón. Proveedor de la panadería de Huete en 1506.

- Gavoto, Lorenzo. Arrendador de rentas eclesiásticas en 1504-1509. Contador del obispo en fecha indeterminada. Proveedor de la panadería en Huete en 1505 y 1506.

- Gentil, Andrea. Arrendador de rentas eclesiásticas. 1509.

- Gentil, Peligro (sic). Tal vez sea el mismo Polo (Paolo?) Gentil. Arrendador de beneficios junto con Lorenzo Bosco. 1516.

- Gentil, Polo. Arrendador de rentas eclesiásticas. 1509.

\section{APÉNDICE DOCUMENTAL}

1506, julio, 28. Valladolid.

1506, julio, 3. Huete.

Confirmación por el rey Felipe I de un asiento concertado por el concejo de Huete con unos genoveses, por virtud del cual éstos se hacen cargo del aprovisionamiento de cereal para la panadería de la ciudad, bajo ciertas condiciones.

AGS, RGS, VII, 1506 (Sin foliar).

Don Felipe por la graçia de Dios rey de Castilla etc. Por quanto/por parte de vos el conçejo justiçia regidores cavalleros escuderos/ofiçiales y omes buenos de la çibdad de Huete nos fue fecha re/laçión por vuestra petiçión diziendo que vosotros a causa de la mucha/neçesidad que los annos pasados y este presente anno avía avido/en esa dicha çibdad avíades fecho çierto asiento con un factor/del cardenal de San Jorge, obispo de Cuenca, ginovés que vino/a faser las rentas del dicho cardenal para que, asy del pan que tenía/el dicho cardenal en esa dicha çibdad de los diezmos deste/anno como de lo que troxese de fuera, que daría a esta çibdad/para la panadería della çinco mill fanegas de trigo y dos/mill y quinientas fanegas de çevada y çenteno con tanto que le fuese/pagado la libra del pan de trigo a quatro mrs. y la de çenteno/y çevada a çinco blancas, del qual dicho asiento synado de/escrivano público fazíades presentaçión ante nos en el nuestro Consejo y/por que aquél toviese mayor firmeza nos suplicávades y/pedíades por merçed lo mandásemos confirmar y proveyésemos/en ello commo la mi merçed fuese. Su tenor del qual dicho asiento/es éste que se sigue: 
En la noble çibdad de Huete a tres/días del mes de jullio anno del nasçimiento de nuestro salvador/lhesu Christo de mill y quinientos y seis annos. Este dicho día se/yendo juntados a conçejo los honrrados sennores conçejo/justiçia, regidores, cavalleros, escuderos, ofiçiales y omes buenos/de la dicha çibdad en la camara de su ayuntamiento a campana/tannida y a su voz de pregonero segund que lo han de uso y de/costumbre de se juntar espeçialmente seyendo presentes el sennor/bachiller Luis Peres de Palençia, teniente de corregidor en la dicha çibdad/y su tierra por el sennor Mosen Fernando de Rebolledo corregidor de la/dicha çibdad y su tierra por sus altesas, regidores de cavalleros/y escuderos Rodrigo del Castillo, Fernando de Calahorra y Andrés Gonçales/y Bernaldino de la Torre y Alonso del Castillo, veyntes del gremio/(fol. 1 v. ${ }^{\circ}$ ) de cavalleros y escuderos el bachiller Juan Falcón y Alonso de Parada y Diego del/Castillo y Alonso Méndez y Fernando Ortis y Francisco Ferrandes y Álvaro de la Torre/el viejo, veyntes de los onbres buenos del común Martín de Villa/real y el bachiller Diego de Villena y Álvaro del Castillo el más moço,/Gabriel de Coçentaina, Miguel de la Penna Cabda y Pedro de Valdel/moro y Gerónimo de la Penna, Antonio del Castillo, Alonso de Soria,/procurador de cavalleros y escuderos Pedro de Santa Cruz, procurador del común/de la çibdad Pedro de Lorençio Martines y Nicolás Martines, procurador del/común de la tierra y en presençia de mí el escrivano público y testigos/deyuso escritos otorgaron los dichos sennores conçejo, justiçia/regidores, cavalleros, escuderos, ofiçiales y omes buenos/todos juntos commo dicho es que por razón que ellos/ovieron comentado al dicho sennor teniente y a Pedro de Santa/Cruz, procurador de los sennores cavalleros y escuderos y a Pedro de Lorençio Martines, procurador del común de la dicha çibdad y a Fernando Ortis y a Fernando de Calahorra/y Álvaro del Castillo el más moço y a Rodrigo del Castillo veçinos de la/dicha çibdad para que diesen asyento con el contador Viçençio/Ferrer para la panadería de la dicha çibdad para el anno/venidero, y ellos de una parte y el contador Viçençio Ferrer/y Lorençio Gavoto su mayordomo de la otra heran conçertados/e ygualados para que los dichos Viçençio Ferrer y Lorençio/Gavoto tomasen la panadería desta çibdad para dar/en ella siete mill y quinientas fanegas de pan, las çinco/mill fanegas de trigo y las dos mill y quinientas fanegas/de çevada y çenteno que él quisiere dar, en esta manera: la libra/de pan cozido de trigo a quatro mrs. y la libra de pan de çenteno cozido y de la çevada a çinco blancas, para que estas dichas/siete mill y quinientas fanegas de pan en la manera que dicha es/se gasten desde primero día del mes de setiembre deste presente/anno fasta en fin del mes de jullio del anno primero venidero/segund que los sennores del conçejo las repartieren y mandaren/dar cada día. Otrosy con condiçión que los sennores del conçejo desta/çibdad sean obligados de traer liçençia 
de sus altesas para que/los dichos Viçençio Ferrer y Lorençio Gavoto puedan servir la/dicha panadería a los preçios y segund que aquí se asentare/y que lo puedan servir non embargante que sean estrangeros se/gund que se troxo el anno pasado para Lorençio Gavoto, y que se traiga/de aquí a quinze días del mes de agosto primero, la qual traiga/la dicha çibdad a su costa dentro del dicho término y que sy no la/traxere que la dicha yguala sea ninguna y que en el dicho término los/dichos provisor y Viçençio Ferrer y Lorençio Gavoto no puedan/sacar pan fuera de la jurisdiçión desta çibdad ni otro por/ellos. Otrosy que la dicha çibdad sea obligada de gastar/en todo el dicho tiempo las dichas siete mill y quinientas fanegas/(fol. 2) de pan a los dichos preçios y de las pagar las que no se gastaren a los/dichos preçios en fin del mes de agosto del anno venidero. Otrosy/con condiçión que por quanto las çinco mill y quinientas fanegas de/pan son de las que perteneçen al reverendo sennor cardenal en esta/çibdad y su tierra y partido, y algunas d'ellas están en arrenda/das veçinos d'esta çibdad y su tierra, que los dichos Viçençio Ferrer/y Lorençio Gavoto sean obligados a faser todas las diligen/çias que según las condiçiones de las rentas pueden faser/fasta el braço seglar, y que aquel entregado a la/parte de la dicha çibdad sea obligada a cobrar el dicho/pan de los dichos arrendadores y lo que no se pudiere cobrar/fazienzo las dichas diligençias que se descuente de las/dichas çinco mill y quinientas fanegas de pan que ay en este/partido y que aquéllas que asy faltaren de esta manera no sean obli/gados los dichos Viçençio Ferrer y Lorençio Gavoto a las complir nin la dicha çibdad a gelas pagar. Otrosy que el dicho contador/Lorençio Gavoto dé el pan a las panaderas que quisiere y aquéllas pueda quitar y poner quando quisiere por que den buen pan/y que sean las panaderas a contentamiento de los sennores del conçejo/. Otrosy que si algún conçejo de la tierra de la dicha çibdad se pusiere/en defender o en alçarse con el dicho pan que perteneçe al dicho carde/nal que la dicha çibdad sea obligada a dalles favor e/ayuda e gente para traello, y que sy no se troxere a la dicha/çibdad que así mesmo les sea fecho descuento del dicho pan que así/han de dar, y la dicha çibdad no sea obligada a lo pagar/y con condiçión que no se reçiba el conçejo nuevo fasta que jure/en forma de complir todo lo aquí contenido, lo qual así mismo nos/otros juramos. Por tanto que ellos avían y ovieron por bueno el dicho asiento y conçierto en la manera que dicha es y se obligavan y obli/garon de lo así tener y mantener y guardar y complir según dicho es/y de no yr nin venir contra ello agora nin en tiempo alguno so pena/de dos mill ducados de oro para los dichos Lorençio Gavoto y Viçen/çio Ferrer, y la pena pagado o non que esta carta sea firme. Para lo/qual asy tener y guardar y complir dixeron que obligavan y obligaron/a sy mismos y a todos sus bienes y a los bienes del dicho conçejo así/muebles como raises avidos y por aver, y 
demás d'esto que/pidían y pidien a todas y qualesquier justiçias que fuesen, ante quien esta carta pareçiese y d'ella fuese pedido complimiento de justiçia/que se lo fiziesen asy tener y guardar y complir y aver por firme bien/asy como sy por sentençia definitiva de jues competente en todo fuesen/condenados. Çerca de lo qual renunçiaron y partieron de sí y de su/favor y ayuda todas y qualesquier leyes y fueros y derechos/y hordenamientos reales canónicos y çiviles fechos y por faser/toda exebçión de dolo y enganno y benefiçio de restituçión/(fol. $2 \mathrm{v}^{\circ}{ }^{\circ}$ ) y otras qualesquier leyes y fueros y derechos y premáticas sançio/nes que en su favor sean que les non valan en juizio nin fuera del/y la ley del derecho que dise que general renunçiaçión fecha que no vala./En fe de lo qual otorgaron esta dicha carta ante mí dicho escrivano y testigos deyuso/escritos e me rogaron que la escriviese o fiziese escrevir y la sy/nase de mi sygno. Testigos que fueron presentes a lo que dicho es Ugenio, veçino de Horcajada, y Diego de Medina y Pedro Lorençio, veçinos de la/dicha çibdad. $Y$ yo Fernán Quixada, escrivano. $Y$ entregaron a los procuradores y regidores que lo firmasen de sus nombres/. El bachiller Luis Peres, Pedro de Santa Crus por Pedro de Lorençio Martines, Nicolás Martines, Rodrigo del Castillo,/Fernando de Calahorra, Alvaro del Castillo, Bernaldino de la/Torre. En la dicha çibdad de Huete este dicho día mes y anno susodichos/en presençia de mí el dicho escrivano y testigos deyuso escritos el dicho Viçençio Ferrar/otorgó semejante obligaçión que la susodicha que la dicha çibdad otorgó/seyéndole leyda delante y dio por sus fiadores para tener y guardar/y complir todo lo susodicho al reverendo sennor Miçer Agostín d'Espindola/prothonotario apostólico y a Don Pedro de Acosta, abad de Santiago, los quales todos/y él todos de mancomún y cada uno por sí yn solidum se obligaron de/tener y guardar y complir todo to que dicho es y la dicha çibdad otorgó so pena de los/dichos dos mil ducados de oro para la dicha çibdad y la pena pagada o non/que esta carta sea firma para lo qual obligaron a sy mismos y a todos sus/bienes muebles y raises avidos y por aver espirituales y temporales y dieron/poder a todos $y$ cualesquier justiçias y renunçiaron qualquier privilegio o esençión de/juridiçión que tengan y renunçiaron todas las leyes y fueros y derechos que en su favor/sean y la ley del derecho que dise que general renunçiaçión no vale con tanto que las/dichas panaderas las ponga Lorenço Gavoto y sy no fisieren buen pan de dar/y de tomar que la justiçia y regidores las quiten y pongan otras. Testigos presentes Alonso Alvares/clérigo, y Alvaro del Castillo el mayor, y Alvar Garçía, vesino de Cuenca y yo Fernán Quexada,/escrivano. Agostín Espínola provisor. Pero de Acosta. Viçençio Ferrer. Fernán Quexada. Lo/qual todo visto en el mi Consejo fue acordado que devía mandar dar esta mi carta/para vos en la dicha razón. Y Yo tóvelo por bien y por la presente confirmo/y apruevo el dicho asiento y capi- 
tulaçión que desuso va incorporado y mando/que se guarde y cumpla segun y commo en él se contien non embargante qualquier defen/dimiento que esté puesto para que ginoveses ni otra persona estrangera alguna/no pueda tener panadería ni ofiçio desta calidad en el obispado de Cuenca/ca por la presente en quanto a lo susodicho dispenso, con ello quedando en su fuerça/y vigor para los otros y los relievo a los dichos Viçençio Ferrer y Lorenço Gavoto/de qualesquier penas que por lo que dicho es les puedan ser ynputadas. Lo qual/todo mando que se haga y cumpla así con tanto que sy alguna persona quisiere/vender pan a más baxo preçio de lo en esta mi carta contenido que lo pueda faser syn/embargo del dicho asiento y de la dicha confirmaçión. $Y$ los unos nin los otros/etc. Dada en la villa de Valladolid XXVIII días de jullio de I II D y VI annos/Yo el rey. Yo Pero Ximenes secretario del rey la fis escrevir por su mandado. 